\title{
FILOSOFIA DA HISTÓRIA E DIREITO EM KANT
}

\author{
Antônio Djalma Braga Junior ${ }^{1}$
}

Resumo: Este trabalho tem como objetivo apresentar uma discussão inicial da Filosofia da História de Kant e sua relação com o Direito, tal como compreender e analisar o que julgamos ser um aspecto central deste filósofo alemão: o fato de que a liberdade está por trás do progresso da humanidade. Defender esta centralidade nos leva ao problema que pretendemos investigar durante a execução deste trabalho: a que tipo de liberdade e que tipo de progresso podemos nos referir no pensamento de Kant ao proferirmos tal afirmação? Um estudo da liberdade no âmbito de uma Filosofia da História faz com que nos deparemos com algumas premissas, como por exemplo a ideia de que a história da humanidade está sempre em uma ascensão do mais primitivo para o mais civilizado dos mundos; ou de que estamos em uma ascensão à paz perpétua e ao esclarecimento; de que caminhamos rumo a uma vida cosmopolita. Tais premissas nos revelam, de antemão, uma noção de liberdade e, diante disso, vemos que estas prerrogativas iniciais nos levam a crer que a humanidade se encontra em um contínuo progresso que tem em sua base um ideal de liberdade. Com efeito, mediante pesquisa bibliográfica, vamos examinar neste artigo apenas uma das inúmeras formas de interpretar a Filosofia da História de Kant, procurando analisar a tese de que a liberdade humana, em seu sentido externo, se encontra em um contínuo progresso, podendo visualizar-se a partir da ótica do Direito.

Palavras-chave: Filosofia da História - Direito - Liberdade

\section{Nota sobre abreviaturas}

As obras de Kant que são utilizadas no presente trabalho estão em acordo com as edições disponíveis em português e também com a edição da Academia (Kants gesammelte Schriften: herausgegeben von der Deutschen Akademie der Wissenschaften, anteriormente Königlichen Preussischen Akademie der Wissenschaften, 29 vols. Berlin, Walter de Gruyter, 1902), disponível no site www.korpora.org/kant/verzeichnisse-gesamt.html.

As abreviaturas das obras de Kant utilizadas no presente trabalho são as seguintes:

KrV - Kritik der reinen Vernunft - Crítica da Razão Pura (A 1781, B 1789);

GMS - Grundlegung zur Metaphysik der Sitten - Fundamentação da metafísica dos costumes (1785) (AA 04);

\footnotetext{
${ }^{1}$ Doutorando em Filosofia pela UFPR. Orientador: Prof. Dr. Vinicius Berlendis de Figueiredo.
} 
$\mathrm{IaG}$ - Idee zu einer allgemeinen Geschichte in weltbürgerlicher Absicht - Ideia de uma história universal de um ponto de vista cosmopolita (1784) (AA 08);

KpV - Kritik derpraktischen Vernunft - Crítica da razão prática (1788) (AA 05);

KdU - Kritik der Urteilskraft - Crítica da faculdade de julgar (1790) (AA 05);

MAM - Mutmaßlicher Anfang der Menschheitsgeschichte - Começo conjectural da história humana (1786) (AA 08)

WA - Beantwortung der Frage: Was ist Aufklärung? - Resposta à pergunta: o que é o Esclarecimento? (1786) (AA 08)

\section{Introdução}

Este trabalho tem como objetivo apresentar uma discussão inicial da Filosofia da História de Kant e sua relação com o Direito, tal como compreender e analisar o que julgamos ser um aspecto central deste filósofo alemão: o fato de que a liberdade está por trás do progresso da humanidade. Defender esta centralidade nos leva ao problema que pretendemos investigar durante a execução deste trabalho: a que tipo de liberdade e que tipo de progresso podemos nos referir no pensamento de Kant ao proferirmos tal afirmação?

Sabe-se que além do sistema Crítico, Kant elaborou uma série de escritos que fundamentam sua Filosofia da História. No presente trabalho procurarei analisar esta ideia de liberdade levando em conta alguns aspectos textuais da Crítica de Kant, mas também aspectos que se expandem para além dos escritos Críticos, passando nosso olhar por conceitos que se encontram nas obras Ideia de uma história universal de um ponto de vista cosmopolita (IaG, AA 8) e Resposta à pergunta: o que é o esclarecimento? (WA, AA 8), publicadas em 1784; Apreciação da obra de Herder: ideias em vista de uma filosofia da história da bumanidade (RezHerder, AA 8), de 1785; e o Começo conjectural da bistória bumana (MAM, AA 8), publicada em 1786.

Um estudo da liberdade no âmbito de uma Filosofia da História, objetivo que nos propomos neste texto, faz com que nos deparemos com algumas premissas, como por exemplo, a ideia de que a história da humanidade está sempre em uma ascensão do mais primitivo para o mais civilizado dos mundos; ou de que estamos em uma ascensão à paz perpétua e ao esclarecimento; de que caminhamos rumo a uma vida cosmopolita. Tais premissas nos revelam, de antemão, uma noção de liberdade e, diante disso, vemos que estas prerrogativas iniciais nos levam a crer que a humanidade se encontra em um contínuo progresso que tem em sua base um ideal de liberdade.

Com efeito, vamos examinar neste artigo apenas uma das inúmeras formas de interpretar a Filosofia da História de Kant, procurando analisar a tese de que a liberdade 
humana, em seu sentido externo, se encontra em um contínuo progresso, podendo visualizar-se a partir da ótica do Direito.

\section{O progresso da humanidade na história e a liberdade em seu sentido externo}

Ao analisarmos o conceito de liberdade no conjunto das obras de Kant perceberemos que esta liberdade é vista como algo que se opõe à natureza. Tomando como base a obra Começo conjectural da história bumana (MAM, AA 8), vemos que a história da humanidade começa com um "sim" à liberdade, e, consequentemente, com um "não" à Natureza, ação que fora interpretada ao longo dos tempos como uma falha, com uma atitude má, com uma "queda", como um não a Deus. Podemos verificar isso no início da obra MAM quando Kant diz:

Somente o instinto, esta voz de Deus, à qual obedecem todos os animais, é que devia guiar a nova criatura. Esse instinto permitia-lhe comer algumas coisas e lhe proibia outras (Gênesis, 32-3). (...) Enquanto o homem inexperiente obedecia à voz da natureza, encontrava-se bem. Mas logo a razãa começa a instigá-lo e estabelece um paralelo entre o que ele havia consumido e os dados de outro sentido independentemente do instinto, a visão talvez, desencadeando uma analogia entre esses dados e as impressões anteriores; ela buscará estender seus conhecimentos relativos aos alimentos além dos limites do instinto (Gênesis, 3:6). Eventualmente, essa tentativa poderia ter sido bastante bem-sucedida, mesmo sem o instinto, à condição de não tê-lo contrariado. No entanto, resulta ser uma qualidade da razão poder, com a ajuda da imaginação, provocar de modo artificial, novos desejos que, além de não se fundarem numa necessidade natural, estão com ela em contraste direto $(. . .)^{2}$.

Esse contraste que a razão provoca revela a capacidade que o homem tem de transpor os limites que a natureza lhe impôs, limites estes que são mantidos em todos os animais, mas que a razão possibilita superar. Kant afirma que juntamente com certa satisfação de poder ir além da natureza, surgiram ansiedade e medo, pois a infinidade de opções que se abria a partir disso revelava ao homem o problema de não saber escolher além do que seu instinto natural the sugeria. Todavia, este contato com a liberdade tornou este caminho um caminho sem volta: é impossível para ele agora voltar a ser dominado pelo instinto.

${ }^{2}$ KANT, Começo conjectural da história humana, p. 16. 
Deste modo, nos vemos diante do problema que pretendemos analisar durante este artigo: se a história da humanidade se inicia com um não à Natureza e a Deus, de que tipo de progresso estamos realmente falando? A que tipo de Liberdade Kant está se referindo? E ainda, qual o fundamento desta noção específica de liberdade?

Para responder a estes questionamentos, vamos nos servir da análise de Otfried Höffe.

Höffe olha para a filosofia da história de Kant a partir das três perguntas fundamentais que Kant procura responder em seus escritos, a saber: $\mathrm{O}$ que posso Saber? O que devo fazer? E o que me é permitido esperar? Em sua obra intitulada Immanuel Kant (2005) ele procura descrever sua interpretação das obras kantianas nos fornecendo uma chave de leitura atraente e significativa. Höffe analisa os escritos do filósofo alemão procurando nos mostrar que a primeira destas perguntas fundamentais diz respeito às ideias presentes na primeira Crítica, à uma filosofia teórica, que procurará estabelecer os limites do conhecimento por meio do empreendimento crítico. Já a pergunta o que devo fazer está diretamente ligada à filosofia prática de Kant, ao campo da filosofia moral. Por fim, na terceira pergunta, Kant se aventura no campo do que ainda está por vir, olha para a história e tenta enxergar o que ainda não veio. Esta investigação sobre o que me é permitido esperar tem como fundamento a análise da própria história, mas também sobre a moral, e se faz necessário aqui compreender um aspecto dos escritos kantianos que é fundamental, a saber, o problema da mediação entre natureza (aquilo que é a realidade e o que podemos conhecer desta realidade) e a moral (aquilo que deveria ser).

A partir disso, Höffe afirma que a resposta ao que nos é permitido esperar fundamenta-se na prática da liberdade humana e pode ser apresentada em duas partes: uma se propõe a analisar a liberdade humana em seu sentido externo e outra parte analisará a liberdade humana em seu sentido interno. A primeira será trabalhada pela filosofia da história e vai alcançar êxito em suas análises do Direito e a segunda será trabalhada pela filosofia da religião. Höffe tem como objetivo demonstrar que estas duas partes não concorrem entre si, mas ao contrário, complementam-se, do mesmo modo, não procuram acrescentar nada ao empreendimento crítico em seu sentido teórico, não entram no campo do que podemos conhecer, mas somente no sentido prático, no campo da liberdade e da moral, ou seja, para utilizar as palavras do próprio Höffe:

Filosofia da História e Filosofia da Religião não prolongam, em primeira linha, a filosofia teórica mas a filosofia prática; elas não estendem o campo do conhecimento. Seus objetos não têm nenhuma realidade objetiva, mas uma realidade prática ${ }^{3}$.

${ }^{3}$ HÖFFE, Immanuel Kant, p. 270 
No que diz respeito à primeira parte da resposta à pergunta sobre o que me é permitido esperar, Höffe nos conduzirá pelo caminho da filosofia da história, que compreende a liberdade humana em seu sentido externo, sob a ótica das leis criadas pelo Direito. E ainda que esta filosofia da história não esteja submetida ao crivo da Crítica, pois encontram-se em textos de natureza popular, contém em si aspectos próprios da Crítica: "contém uma espécie de crítica da razão histórica"4.

A História interessa ao homem não em seu sentido epistemológico, não pensandoa como uma metodologia própria da disciplina denominada História, mas interessa do ponto de vista de uma filosofia prática, uma filosofia moral. Justamente a partir disso, na interpretação de Höffe, "Kant defende uma interconexão com a crítica transcendental da razão e pergunta sob que condições dependentes da experiência o curso da História aparece como racional e dotado de sentido" 5 . Deste modo, vemos que o fundamento desta filosofia da história assenta-se no que ficará conhecido como o idealismo transcendental de Kant, fundamento este que nos remete à uma ideia de liberdade em seu sentido externo, em sua constituição jurídica (Filosofia do Direito). Que implicações isso nos traz? É o que veremos no tópico a seguir.

\section{Filosofia da história e direito}

Ora, veremos que os escritos de Kant não ignoram que há instaurado na História um quadro por vezes desolador, sem sentido e até mesmo absurdo. Mas ao mesmo tempo defende a esperança de que haverá um sentido racional no curso desta mesma história absurda. Höffe escreve que:

Conquanto a História com toda a sua desgraça apareça como sem sentido, talvez até absurda, Kant se pergunta se apesar disso não podemos descobrir nela um sentido, não na história de indivíduos e grupos mas na história de toda a humanidade, da história mundial. Por isso Kant procura para a história mundial o primeiro início e o último objetivo, o fim terminal ${ }^{6}$.

Em relação ao início da História não nos é possível conhecê-la objetivamente, mas apenas realizar conjecturas e escrever ficções sobre ela. Mesmo assim, diante das dificuldades de objetivação deste início da história, é possível, segundo Kant, ao menos deduzir algumas ideias das experiências pelas quais esta espécie humana passou e realizar analogias a partir de suposições do mundo natural. Embora Kant escreva que estas conjecturas “(...) devem

\footnotetext{
${ }^{4}$ HÖFFE, Immanuel Kant, p. 271

${ }^{5}$ HÖFFE, Immanuel Kant, p. 271

${ }^{6}$ HÖFFE, Immanuel Kant, p. 272
} 
apresentar-se como um exercício concedido à imaginação, acompanhada da razão, para o divertimento e a saúde da mente. Em nenhum caso devem ser encaradas como algo sério"7, procura tomar nestas conjecturas, como fio condutor, o livro do Gênesis da bíblia e descrever uma primeira ideia do desenvolvimento da liberdade a partir da disposição natural que a natureza humana dispõe ${ }^{8}$. Neste início da História, o homem vive unicamente segundo as disposições de seus instintos, de sua natureza animalesca, permanecendo ignorante quanto à sua capacidade de liberdade e de racionalidade. Justamente quando o homem descobre em sua constituição humana a capacidade de escolher, percebe a sua liberdade, ele é capaz de se libertar do instinto e contrariar o que sua própria natureza lhe sugere. É neste sentido que podemos compreender que a história da liberdade humana começa com um dizer não à natureza. Esta interpretação nos mostra que o progresso ao qual Kant escreve é um progresso que leva o homem a superar o seu estado de natureza e permite a sua entrada no estado de liberdade: é uma filosofia da história que compreende o progresso como uma ascensão para a liberdade. Que tipo de liberdade? Uma liberdade exterior:

A história deve progredir para um a convivência dos homens em liberdade exterior, de modo que todas as forças e disposições possam desenvolver-se. A convivência em liberdade exterior efetiva-se no Estado de Direito (no Estado justo), que põe termo à barbárie e ao despotismo entre os homens. O sentido da História encontra-se na instituição de estados de direito e de uma convivência legal (justa) dos Estados entre si, em constante progresso do direito de toda a humanidade, até que finalmente se tenha formado, nos limites de uma federação de povos, uma comunidade de paz que abarque o mundo todo ${ }^{9}$.

A ideia de uma comunidade de paz deve ser o objetivo final da humanidade, o fim terminal; esta constituição tornar-se-á efetiva quando houver um Estado de Direito que ponha fim à barbárie e valorize um progresso a partir de uma ação política, a partir das relações de direito em âmbito nacional e internacional. Acontece que nesta análise de Höffe vemos que o indivíduo não conseguirá, por si só, alcançar esta finalidade última à qual a natureza humana o dispôs teleologicamente, mas somente a espécie, o gênero humano, conseguirá atingir este fim terminal (Endzweck) ${ }^{10}$, através de gerações sucessivas e por meio de uma organização jurídica e política consolidada pelas leis. Isso está descrito na segunda proposição da obra IaG de Kant: "No ser humano (como única criatura racional sobre a

${ }^{7}$ KANT, Começo conjectural da história humana, p. 14

${ }^{8}$ Cf. HÖFFE, Immanuel Kant, p. 272

${ }^{9}$ HÖFFE, Immanuel Kant, p. 274.

${ }^{10}$ Cf. KANT, Crítica da faculdade do juízo, p. 40; 
Terra), as predisposições naturais que visam ao uso de sua razão estão para ser desenvolvidas, na íntegra, somente na espécie e não no indivíduo"11.

Corrobora para esta compreensão o fato de que o desenvolvimento da liberdade humana ocorre em seu sentido externo, na ideia de que a história só poderia se restringir a fatos empíricos, a ações dos indivíduos, e não em relação à intenção dos mesmos. Diante disso, o progresso da humanidade não reside na consumação da moralidade ou de uma liberdade que possa ser compreendida em seu sentido interno, mas, ao contrário,

Kant limita o progresso à justiça política, a relações jurídicas no âmbito nacional e internacional, que como relações de direito incluem a faculdade de coagir. Porque na História se trata de acontecimentos exteriores, tampouco é de modo algum possível que seu sentido último se encontre em um progresso "interior", em um desenvolvimento da disposição moral. O progresso só pode ser esperado no âmbito exterior, na instituição de relações de direito segundo critério da razão prática pura ${ }^{12}$.

É diante disso que o progresso, para Kant, só pode ser tomado analisando as relações jurídicas e como elas foram materializadas em forma de leis. Estes fenômenos jurídicos constituem a prova de que a humanidade tem caminhado rumo ao progresso, conferindo ao longo dos tempos cada vez mais liberdade ao homem. E embora o curso da história contenha em si absurdos e barbáries, é possível, ao analisarmos o Direito, que tenhamos avançado na finalidade da natureza em desenvolver no homem suas disposições naturais. E neste sentido, sabendo que tais mudanças ocorrem lentamente, não podendo ser percebida no indivíduo, mas somente na espécie, no gênero humano como um todo, Kant reconhece o progresso para o melhor, pois, enquanto elas acontecem, são tomadas como fenômenos. Vemos, assim, que a tomada das ações do indivíduo na história como fenômeno remete à teoria do idealismo transcendental kantiano, teoria esta que nos impede de considerar algo que não seja fenomenal (ou que seja suprassensível) como fundamento para a defesa desta tese ${ }^{13}$.

Mas em que sentido é possível identificarmos esta melhora na História da humanidade em Kant? Höffe nos mostra que há três possibilidades: “ao lado do (1) contínuo avanço para o melhor, existem (2) a possibilidade de um constante declínio para o pior, até que enfim a própria humanidade se extermine, e (3) a possibilidade de que tudo continuamente se mantenha na mesma"14. O fato é que nenhuma destas posições pode ser provada em sentido teórico, empírico ou especulativo, restando-nos apenas um saber prático a priori da História que irá desembocar em um progresso do Direito, que não tem em si uma

${ }^{11} \mathrm{KANT}$, Ideia para uma história universal de um ponto de vista cosmopolita, p. 26;

12 HÖFFE, Immanuel Kant, p. 275.

${ }^{13}$ KANT, Crítica da razão pura, p. 374;

${ }^{14} \mathrm{HÖFFE}$ Immanuel Kant, p. 275; 
necessidade teórica, mas sim uma necessidade prática, necessidade esta que contraria a tese de que não há um sentido no curso da história: "a concepção da história como um progresso do Direito rejeita o pensamento da ausência de sentido"15. Com isso, pretendemos demonstrar aqui que o Direito, ao ser utilizado no sentido de uma razão prático-jurídica, que propõe aos homens uma forma de viver segundo princípios, e não meramente segundo instintos, se mostra realizável na natureza. Esta ideia corresponde à teleologia kantiana de que todas as disposições naturais dos homens tendem a se desenvolver no curso da história, sendo que estas disposições chegam em seu desenvolvimento pleno somente no gênero humano como um todo, e nunca no indivíduo, por meio das diversas sucessões de gerações. A história, deste modo, seria o palco onde a natureza empreende o desenvolvimento da espécie humana.

Contudo, há um elemento indispensável na forma como Kant compreende este progresso da humanidade e faz-se necessário agora explicitarmos de maneira organizada. Estamos falando da característica antagônica que os homens apresentam na sua vivência em sociedade e que Kant chama de sociabilidade insociável. Isso está demonstrado na quarta proposição da obra IaG:

Os meios que a natureza emprega a fim de permitir o desenvolvimento de todas as predisposições dos seres humanos é o seu antagonismo das mesmas na sociedade, na medida em que este antagonismo acaba se tornando a causa de uma organização da sociedade regida pelo direito ${ }^{16}$.

Esta ideia consiste no fato de que os homens tendem a desenvolver todas as suas disposições naturais e neste processo inclina-se à uma vivência em sociedade, causando um antagonismo com a propensão do homem em isolar-se. Da mesma forma que esta convivência social se apresenta como necessária ao sujeito, ele também procura se isolar, a viver de maneira pessoal, sozinho, contrariando as regras sociais criadas pelo grupo, procurando seguir aquilo que sua cabeça manda individualmente, criando este antagonismo.

Os seres humanos têm uma inclinação a se associar uns com os outros porque nesta condição sentem-se mais humanos, quer dizer, em melhores condições de desenvolver suas predisposições naturais. Mas eles têm também uma forte tendência a se isolar, porque encontram em si mesmos o traço antissocial que os predispõem a querer dirigir tudo somente para seus

\footnotetext{
${ }^{15}$ HÖFFE, Immanuel Kant, p. 276

${ }^{16}$ KANT, Ideia para uma história universal de um ponto de vista cosmopolita, p. 29;
} 
próprios fins e, portanto, deve-se esperar que encontrem resistência de todos os lados, assim como sabem que eles mesmos tendem a resistir aos outros ${ }^{17}$.

Esta sociabilidade insociável leva os homens a superarem sua ociosidade e sua inércia, pois estes desejam parecer honrosos diante da sociedade e com isso adquirir poder e uma posição de status diante dos demais. Como resultado deste processo, o homem produz cultura e arte, pois, do contrário, se extinguiriam. Neste ponto, Kant nos mostra que os talentos são desenvolvidos no homem, de modo que o primitivo impulso natural seja convertido em princípios morais e leve a sociedade a viver de maneira pacífica. Graças a esta sociabilidade insociável, que produz um antagonismo e um constante conflito, se consegue dar um sentido e uma finalidade para a natureza racional dos homens:

Por esta razão deve-se agradecer à natureza por sua belicosidade, por sua vaidade competitiva e ciumenta, por seu apetite insaciável por propriedade e até mesmo por poder. Sem isso todas as predisposições humanas naturais e excelentes jazeriam em sono eterno, incapazes de se desenvolver. Os seres humanos desejam harmonia, mas a natureza sabe melhor o que é bom para sua espécie: ela discordará ${ }^{18}$.

Que este antagonismo leve os homens a se desenvolverem, nos parece ser um fato incontestável. Mas, devemos chamar a atenção neste momento de nosso texto para um outro dado importante: diversos males surgem a partir desta sociabilidade insociável, diversas guerras são travadas por conta deste antagonismo que a natureza dispôs nos homens. Por conta disso é que Höffe nos ajudará a compreender que, segundo Kant, para alcançarmos a finalidade de uma comunidade de paz, baseada em um ideal cosmopolita, precisamos passar por um processo de humanização das guerras, tornando-as cada vez mais raras e, por fim, extingui-las completamente. Isso é difícil de ser concebido quando se tem em mente esta sociabilidade insociável e embora Kant se mostre otimista quanto a este progresso - mesmo observando que a História atenta de maneira contrária a toda e qualquer prerrogativa de certeza deste progresso - Höffe escreve que "a garantia que a sociabilidade insociável oferece para o fim terminal da História não consiste em uma certeza que permita predizer teoricamente o futuro da paz perpétua"19. Ao perceber o interesse dos homens em sua busca por justiça, ou melhor, a formas justas de governo, de Estado, sobretudo no fervor da Revolução Francesa, este otimismo kantiano parece estar fundamentado em uma prova

${ }^{17} \mathrm{KANT}$, Ideia para uma história universal de um ponto de vista cosmopolita, p. 30;

${ }^{18}$ KANT, Ideia para uma história universal de um ponto de vista cosmopolita, p. 31.

${ }^{19}$ HÖFFE, Immanuel Kant, p. 277; 
histórica, prova esta que vê neste acontecimento da liberdade do século XVIII, o progresso da humanidade por meio do Direito.

\section{Considerações finais}

Vimos a partir destas linhas uma das formas de entendermos a Filosofia da História de Kant, na qual procuramos demonstrar que a história humana representada pelas ações humanas pertence, portanto, ao reino dos fenômenos, ao reino da natureza, sendo determinada por este tipo específico de legislação, pressupondo, a partir da lei da causalidade, que todo e qualquer evento possui uma linha temporal que o sucede.

Uma vez que a história pertence ao reino da natureza, deve excluir por completo a liberdade em seu sentido interno, em seu sentido moral, para que não se contradiga ao seu idealismo transcendental, pois não se pode a partir desta ideia inserir no mundo dos fenômenos aquilo que pertence ao âmbito noumênico. Isso corrobora com a tese de Höffe de que o progresso da humanidade pode ser entendido apenas do ponto de vista da legalidade do direito, ou do ponto de vista político, no sentido de uma liberdade externa.

Sabemos que há outras formas de entender a filosofia da história kantiana, sobretudo a partir da ideia da liberdade em seu sentido interno, do ponto de vista da moralidade, todavia, deixaremos as análises desta tese e de suas implicações para uma outra pesquisa.

\section{PHILOSOPHY OF HISTORY AND LAW IN KANT}

Abstract: This paper aims to present an initial discussion of Kant's Philosophy of History and its relation to the Law, as well as to understand and analyze what we believe to be a central aspect of this German philosopher: the fact that freedom is behind the progress humanity. Defending this brings us to the central issue that we intend to address during the execution of this work: what kind of freedom and what kind of progress can we refer to Kant's thought when we pronounce such a statement? A study of freedom in the context of a philosophy of history forces us to came across with some assumptions, such as the idea that human history is always an ascension from the most primitive to the most civilized of the worlds; or that we are on an ascension to perpetual peace and enlightenment; that we are moving towards a cosmopolitan life. Such premises tell us, in advance, a sense of freedom and, before that, we see that these initial prerogatives lead us to believe that humanity is in a continuous progress that has at its base an ideal of freedom. Indeed, by a bibliographic research, we will examine in this article only one of many ways of interpreting Kant's Philosophy of History trying to analyze the thesis that human freedom, in its external sense, is in a continuous progress, what can be seen from perspective of Law.

Keywords: Philosophy of History - Law - Freedom 


\section{REFERÊNCIAS BIBLIOGRÁFICAS}

HÖFFE, Otfried. Immanuel Kant. Trad. Christian Viktor Hamm, Valério Rohden. São Paulo: Martins Fontes, 2005

KANT, Immanuel. Crítica da razão pura. Tradução de Manuela Pinto dos Santos, $5^{a}$ Edição. Lisboa: Fundação Calouste Gulbenkian, 2001

. Critica da Razão Prática. Edição Bilíngue. Trad. Valério Rohden. São Paulo: Martins Fontes, 2003

Crítica da faculdade do juíro. Trad. de Valério Rohden e Antonio Marques. Rio de Janeiro: Forense Universitária, 2002

Comeşo conjectural da história humana. São Paulo: Editora Unesp, 2010

- Ideia para uma história universal de um ponto de vista cosmopolita. In: Filosofia da História.

Tradução Cláudio J. A. Rodrigues. $1^{a}$ edição. São Paulo: Ícone, 2012 (Coleção fundamentos da filosofia)

Fundamentação da Metafísica dos Costumes. In: Os Pensadores. Trad.: Valério Rohden. São Paulo: Abril Cultural, 1974

. "Resposta à pergunta: Que é o Esclarecimento?”. In: Textos Seletos. 7 ed. Petrópolis: Vozes, 2011. (Coleção textos filosóficos) 